\title{
ORIGINAL
}

\section{Clinical characteristics and outcomes of critically ill patients with novel coronavirus infectious disease (COVID-19) in China: a retrospective multicenter study}

Jianfeng Xie', Wenjuan $\mathrm{Wu}^{2}$, Shusheng $\mathrm{Li}^{3}, \mathrm{Yu} \mathrm{Hu}^{4}$, Ming Hu${ }^{5}$, Jinxiu Li ${ }^{6}, \mathrm{Yi}_{\mathrm{i}} \mathrm{Yang}^{1}$, Tingrong Huang ${ }^{7}$, Kun Zheng ${ }^{8}$, Yishan Wang ${ }^{9}$, Hanyujie Kang ${ }^{9}$, Yingzi Huang ${ }^{1}$, Li Jiang ${ }^{10}$, Wei Zhang ${ }^{11}$, Ming Zhong ${ }^{12}$, Ling Sang ${ }^{13}$, Xia Zheng ${ }^{14}$, Chun Pan ${ }^{1}$, Ruiqiang Zheng ${ }^{15}$, Xuyan Li ${ }^{9}$, Zhaohui Tong ${ }^{*^{*}}$, Haibo Qiu ${ }^{1 *}$ and Bin Du ${ }^{16^{*}}$ (D)

C 2020 Springer-Verlag GmbH Germany, part of Springer Nature

\begin{abstract}
Purpose: An ongoing outbreak of coronavirus disease 2019 (COVID-19) emerged in Wuhan since December 2019 and spread globally. However, information about critically ill patients with COVID-19 is still limited. We aimed to describe the clinical characteristics and outcomes of critically ill patients with COVID-19 and figure out the risk factors of mortality.

Methods: We extracted data retrospectively regarding 733 critically ill adult patients with laboratory-confirmed COVID-19 from 19 hospitals in China through January 1 to February 29, 2020. Demographic data, symptoms, laboratory values, comorbidities, treatments, and clinical outcomes were collected. The primary outcome was 28 -day mortality. Data were compared between survivors and non-survivors.

Results: Of the 733 patients included in the study, the median (IQR) age was 65 (56-73) years and 256 (34.9\%) were female. Among these patients, the median (IQR) APACHE II score was 10 (7 to 14) and 28-day mortality was 53.8\%. Respiratory failure was the most common organ failure (597 [81.5\%]), followed by shock (20\%), thrombocytopenia (18.8\%), central nervous system (8.6\%) and renal dysfunction (8\%). Multivariate Cox regression analysis showed that
\end{abstract}

*Correspondence: tongzhaohuicy@sina.com; haiboq2000@163.com; dubin98@gmail.com

1 Jiangsu Provincial Key Laboratory of Critical Care Medicine, Department of Critical Care Medicine, Zhongda Hospital, School of Medicine, Southeast University, Nanjing 210009, Jiangsu, China

${ }^{9}$ Department of Respiratory and Critical Care Medicine, Beijing Institute of Respiratory Medicine, Beijing Chao-Yang Hospital, Capital Medical University, Beijing 100020, China

${ }^{16}$ Medical ICU, Peking Union Medical College Hospital, Peking Union Medical College and, Chinese Academy of Medical Sciences, Beijing 100730, China

Full author information is available at the end of the article Jianfeng Xie, Wenjuan Wu, Shusheng Li, Yu Hu, Ming Hu and Jinxiu Li contributed equally.

\section{亚 Springer}


older age, malignancies, high APACHE II score, high D-dimer level, low $\mathrm{PaO}_{2} / \mathrm{FiO}_{2}$ level, high creatinine level, high hscTnl level and low albumin level were independent risk factors of 28-day mortality in critically ill patients with COVID-19.

Conclusion: In this case series of critically ill patients with COVID-19 who were admitted into the ICU, more than half patients died at day 28. The higher percentage of organ failure in these patients indicated a significant demand for critical care resources.

Keywords: COVID-19, Critically ill, Organ failure, Mortality

\section{Introduction}

Since the first case was reported as Coronavirus Infectious Disease 2019 (COVID-19) in Wuhan in last December [1], there has been more than 14,000,000 laboratory-confirmed cases around the world, among whom more than 600,000 patients have died [2]. As a response, World Health Organization (WHO) declared that the outbreak of COVID-19 constituted a public health emergency of international concerns on January 30, 2020.

The clinical spectrum of COVID-19 ranges from mild to severe, while $5 \%$ of all symptomatic patients with COVID-19 were classified as critical cases (i.e. severe respiratory failure requiring mechanical ventilation, shock, and/or multiple organ dysfunction), with mortality of $49 \%$ [3]. Only a few studies described the characteristics and outcomes of critically ill patients with COVID-19 [">3-6]. Grasselli et al. reported baseline characteristics of 1591 patients with COVID-19 admitted to intensive care units (ICUs) of the Lombardy region, Italy [6]. However, at the time of reporting, 920 patients $(58 \%)$ were still in the ICU. The others were all single-center studies enrolling a small number of ICU patients [3-5]. Yang et al. reported that, among 52 critically ill patients with COVID-19, 37 required mechanical ventilation and 32 died at 28 days [4].

The objective of this study was to describe the clinical characteristics and outcomes of critically ill patients with COVID-19, the disease progression in survivors and non-survivors, and risk factor of case fatality.

\section{Methods}

\section{Study design}

This retrospective, multi-center observational study was conducted in 19 designated hospitals for COVID-19 in Wuhan (Hubei Province), Huangshi (Hubei Province), Shenzhen (Guangdong Province), and (Jiangsu Province) (Table S1). The study was approved by the ethics committee of Jin Yin-tan Hospital (KY-2020-10.02). The informed consent was waived due to the retrospective and observational nature of the study.

All adult patients with COVID-19 who were admitted to ICUs of the participating hospitals between January 1

\section{Take home message}

In this large sample of 733 critically ill patients with COVID-19, more than half patients died at day 28. A high prevalence of organ dysfunction such as respiratory failure, shock and acute renal failure was found during ICU stat. In addition, older age, male sex, malignancies, high APACHE II score, high D-dimer level, high creatinine level and low albumin level were independent risk factors of mortality in critically ill patients with COVID-19. The higher percentage of organ failure in these patients indicated a significant demand for critical care resources.

and February 29, 2020 were included in this study, if they met the following inclusion criteria: $(1)>18$ years of age; (2) laboratory-confirmed diagnosis of COVID-19 [7]; (3) severe respiratory failure requiring advanced respiratory support [i.e. high flow nasal oxygen (HFNO), noninvasive mechanical ventilation (NIV), and invasive mechanical ventilation (IMV)], circulatory shock, or multiorgan failure. There were no exclusion criteria.

\section{Data collection}

For every enrolled patient, we collected demographic data, comorbidities, presenting signs and symptoms, severity of illness, laboratory tests, pharmacological and non-pharmacological treatment during ICU stay, and patient outcome. Laboratory tests included complete blood count, electrolytes, hepatic and renal function tests, coagulation tests, arterial blood gas, biomarkers of inflammation [hypersensitive $\mathrm{C}$-reactive protein (hs-CRP)], and biomarkers of cell injury [lactate dehydrogenase (LDH), hypersensitive cardiac troponin I (hsc$\mathrm{TnI})$ ]. In cases when arterial blood gas analysis was not available, $\mathrm{PaO}_{2} / \mathrm{FiO}_{2}$ ratio was calculated based on Rice equation [8]. Severity of illness was assessed by Acute Physiology and Chronic Health Evaluation (APACHE) II score, based on the worst variables recorded during the first $24 \mathrm{~h}$ of ICU admission. Organ dysfunction was assessed by Sequential Organ Failure Assessment (SOFA) score, together with vital signs and laboratory tests, on day 1, 3, 7 and 14 after ICU admission. Individual organ failure was defined as a component SOFA score greater than 2 [9]. Cardiac injury was defined as serum level 
of hsc-TnI above the upper limit of the reference range $(>28 \mathrm{pg} / \mathrm{mL}$ ).

All patients included in the study were followed up to 28 days or death, which occurred earlier after enrollment. The primary outcome was 28-day mortality after ICU admission. Secondary outcomes included use of lifesustaining treatment [IMV, extracorporeal membrane pulmonary oxygenation (ECMO), and continuous renal replacement therapy (CRRT)], ICU length of stay, virus negative conversion rate and dynamic changes of laboratory tests.

\section{Statistical analysis}

Values were presented as frequency/percentage of a group from which they were derived (categorical variables), or as the mean \pm standard deviation (SD) or median [interquartile range (IQR)] when appropriate (continuous variables). Categorial variables were compared with the use of Chi-square test or Fisher's exact test, while continuous variables were compared with the Student's $t$ test or Mann-Whitney $U$ test.

Three multivariate models were constructed to determine the risk factors of 28-day mortality. First, the multivariate Cox proportional-hazards regression model was used to explore the independent risk factors associated with 28-day mortality. Variables on ICU admission with $P$ value $<0.05$ in univariate analysis or determined as risk factors of mortality in previous studies were entered into the model. Variables with considerable collinearity [e.g. blood urea nitrogen (BUN) and serum creatinine] were carefully selected, and those with more clinical relevance were entered into the model. The final model was tested for proportional hazards assumptions (using Schoenfeld residuals) and nonlinearity in relationship between the log hazard and the covariates (using Martingale-residual plots). Continuous variables with nonlinearity [international normalized ratio (INR), creatinine, and hscTnI] were transformed to categorial variables according to quartiles and then included in the Cox regression model. Second, a frailty Cox model was used to test the intercenter variability based on the first approach. Last, we performed multivariate Cox regression model to adjust for both variables on ICU admission and time-dependent variables (including SOFA, $\mathrm{PaO}_{2} / \mathrm{FiO}_{2}$ ratio, lymphocyte count, albumin, creatinine, LDH, hsCRP, D-dimer, hscTnI, and INR) [10].

The joint longitudinal model was used to analyze the dynamic changes of laboratory tests. Missing data of key variables was summarized in Table S2. We used multiple imputation by chained equation (MICE) which generated values for all missing data using the observed data for all patients (supplements) for multivariate Cox proportional-hazards regression. Given the censored outcome, the cumulative baseline hazard was introduced in the imputation model. Kaplan-Meier survival curve was performed to analyze 28-day survival rates in all patients. All statistical analyses were performed using the RStudio (version 1.2.5019) and Stata (version 15.1), and $P<0.05$ was considered statistically significant.

\section{Results}

\section{Demographic and clinical characteristics}

During the study period, 733 critically ill patients with COVID-19 were admitted to the ICUs of the participating hospitals and thus included in the analysis. The median age was 65 years (IQR 56-73), and 477 (65.1\%) were male (Figure S1). Of these patients, $454(61.9 \%)$ had one or more comorbidities, with hypertension (42\%) as the most common comorbidity, followed by diabetes (18.8\%) and coronary heart disease (12.7\%). The most common presenting symptoms were fever [630 (85.9\%)], dry cough [550 (75\%)], and dyspnea [444 (60.7\%)] (Table 1). The median duration from symptom onset to hospitalization and ICU admission were 6 days (IQR 3-10) and 13 days (IQR 9-20), respectively (Table 2).

\section{Organ failure and life-sustaining treatment in ICU}

Of the 733 patients, respiratory failure was the most common organ failure [597 (81.5\%)], as suggested by $\mathrm{PaO}_{2} / \mathrm{FiO}_{2}$ ratio of $100 \mathrm{mmHg}$ (IQR 40-191). shock was the second most common organ dysfunction [147 (20\%)], followed by thrombocytopenia [138 (18.8\%)], central nervous system [63 (8.6\%)] and renal failure [59 (8.0\%)] (Figure S2). In particular, 357 (59.2\%) out of 603 patients had evidence of cardiac injury. As a result, HFNO, NIV, and IMV were used in 397 (54.2\%), 388 (52.9\%), and 307 (41.9\%) patients, respectively. In patients treated with IMV, duration of HFNO and NIV before IMV was much shorter in survivors than non-survivors [ 2 days (IQR $0-8$ ) vs. 4 days (IQR $1-7$ ), $P=0.039$ ]. Moreover, 297 (40.4\%) and 95 (13\%) patients received vasopressors and CRRT, respectively. Other pharmacological treatments, such as antivirals, corticosteroids, and immunomodulatory therapy, were reported in Table S2.

\section{Clinical outcome and risk factors for case fatality}

Three hundred and ninety-four patients died at day 28 after ICU admission, corresponding to mortality of $53.8 \%$ [95\% confidence interval (CI) 50.1-57.4\%] (Fig. 1). The length of ICU stay was 12 (6-25) days and viral negative conversion rate was $66.3 \%$. Compared with survivors, non-survivors were more likely to be older [68 (IQR 62-75.5) vs. 61 (IQR 51-69), $P<0.001$ ], male $(69 \%$ vs. $60.5 \%, P=0.015)$, and having comorbidities $(67.5 \%$ vs. $55.5 \%, P=0.001)$. The length of ICU stay was significantly longer and the viral negative conversion rate 
Table 1 Characteristics of critically ill patients with COVID-19

\begin{tabular}{|c|c|c|c|c|}
\hline Characteristic & All $(N=733)$ & Survivor $(N=339)$ & Non-survivor $(N=394)$ & $P$ value \\
\hline Age, median (IQR) & $65(56-73)$ & $61(51-69)$ & $68(62-75.5)$ & $<0.001$ \\
\hline Female, $n(\%)$ & $256(34.9)$ & $134(39.5)$ & $122(31)$ & 0.015 \\
\hline $\begin{array}{l}\text { APACHE II score on the first day of ICU } \\
\text { admission-median (IQR) }\end{array}$ & $10(7-14)$ & $7(5-11)$ & $13(10-16)$ & $<0.001$ \\
\hline $\begin{array}{l}\text { SOFA score on the first day of ICU } \\
\text { admission-median (IQR) }\end{array}$ & $4(1-5)$ & $2(0-4)$ & $5(4-7)$ & $<0.001$ \\
\hline No. of comorbidities-median (IQR) & $1(0-2)$ & $1(0-2)$ & $1(0-2)$ & 0.022 \\
\hline Any comorbidity, n (\%) & $454(61.9)$ & $188(55.5)$ & $266(67.5)$ & 0.001 \\
\hline Hypertension, n (\%) & $308(42)$ & $122(36)$ & $186(47.2)$ & 0.002 \\
\hline Diabetes, $n$ (\%) & $138(18.8)$ & $60(17.8)$ & $78(19.8)$ & 0.469 \\
\hline Coronary heart disease, $n(\%)$ & $93(12.7)$ & $38(11.2)$ & $55(14)$ & 0.265 \\
\hline Chronic lung disease, $n(\%)$ & $37(5)$ & $13(3.8)$ & $24(6.1)$ & 0.164 \\
\hline Congestive heart failure, $n(\%)$ & $15(2)$ & $6(1.8)$ & $9(2.3)$ & 0.624 \\
\hline Stroke, $n(\%)$ & $34(4.6)$ & $14(4.1)$ & $20(5.1)$ & 0.544 \\
\hline Chronic renal failure, $n(\%)$ & $13(1.8)$ & $5(1.5)$ & $8(2)$ & 0.570 \\
\hline Malignancies, $n(\%)$ & $24(3.3)$ & $7(2.1)$ & $17(4.3)$ & 0.088 \\
\hline Cirrhosis, $n(\%)$ & $11(1.5)$ & $4(1.2)$ & $7(1.8)$ & 0.508 \\
\hline Immune suppression, $n(\%)$ & $8(1.1)$ & $2(0.6)$ & $6(1.5)$ & 0.297 \\
\hline Connective tissue disease, $n(\%)$ & $5(0.7)$ & $1(0.3)$ & $4(1)$ & 0.380 \\
\hline Ever smoker, $n(\%)$ & $45(6.1)$ & $12(3.5)$ & $33(8.4)$ & 0.007 \\
\hline Ever drinker, $n(\%)$ & $36(4.9)$ & $11(3.2)$ & $25(6.3)$ & 0.053 \\
\hline \multicolumn{5}{|l|}{ Symptoms, $n(\%)$} \\
\hline Fever & $630(85.9)$ & $287(84.7)$ & $343(87.1)$ & 0.352 \\
\hline Cough & $550(75)$ & $254(74.9)$ & $296(75.1)$ & 0.950 \\
\hline Dyspnea & $444(60.7)$ & $163(48.1)$ & $281(71.3)$ & $<0.001$ \\
\hline Diarrhea & $90(12.3)$ & $44(13)$ & $46(11.8)$ & 0.592 \\
\hline Fatigue & $402(54.8)$ & $165(48.7)$ & $237(60.2)$ & 0.002 \\
\hline $\mathrm{HFNO}^{\mathrm{a}}$ & $397(54.2)(50.5-57.8)$ & $185(54.6)(49.2-59.9)$ & $212(53.8)(48.9-58.8)$ & 0.836 \\
\hline Non-invasive ventilation ${ }^{a}$ & $388(52.9)(49.3-56.6)$ & $136(40.1)(34.9-45.4)$ & $252(64)(59.2-68.7)$ & $<0.001$ \\
\hline PEEP, $\mathrm{cmH}_{2} \mathrm{O}$, median (IQR) & $8(6-10)$ & $6(5-8)$ & $8(6-10)$ & $<0.001$ \\
\hline $\mathrm{FiO}_{2}, \%$, median (IQR) & $80(55-100)$ & $60(45-80)$ & $90(75-100)$ & $<0.001$ \\
\hline
\end{tabular}

was significantly higher in survivors. Laboratory tests suggested that white blood cell count, hs-CRP, LDH, hsc-TnI, and D-dimer were higher in non-survivors, suggesting more severe systemic inflammation, cell injury, and coagulopathy (Table S4). Therefore, non-survivors were more severely ill, as suggested by higher APACHE II and SOFA score, more organ dysfunction (Figure S2), more life-sustaining treatments, and lower virus negative conversion rate $(26.2 \%$ vs. $89.8 \%, P<0.001)$ (Table 2 and Figure S3).

No violation against the proportional hazard assumption was detected in the test for 28-day mortality (Table S5). Older age, malignancies, high APACHE II score, high $\mathrm{D}$-dimer level, high creatinine level, high
hscTnI level, low P/F ratio and low albumin level were independent risk factors of mortality in critically ill patients with COVID-19 (Table 3). Similar results were found in the multivariate frailty Cox model and the Cox regression model accounting for the time-varying variables (Tables S6 and S7).

\section{Dynamic changes of laboratory tests and life-sustaining treatment during ICU stay}

From day 1 to day 14 in $\mathrm{ICU}, \mathrm{PaO}_{2} / \mathrm{FiO}_{2}$ ratio and lymphocyte count steadily improved in survivors and remained low in non-survivors (Table S4). In comparison, hs-CRP and LDH levels significantly decreased in survivors but remained higher in non-survivors, whereas 
Table 2 Clinical course and outcome of critically ill patients with COVID-19

\begin{tabular}{|c|c|c|c|c|}
\hline & All $(N=733)$ & Survivor $(N=339)$ & Non-survivor $(N=394)$ & $P$ value \\
\hline \multicolumn{5}{|l|}{ Time course of illness-day, median (IQR) } \\
\hline Symptoms to hospital admission & $6(3-10)$ & $5(2-9.5)$ & $7(3-10)$ & 0.276 \\
\hline Symptom onset to ICU admission & $13(9-20)$ & $13(9-20)$ & $14(10-19)$ & 0.309 \\
\hline \multicolumn{5}{|l|}{ Respiratory support at ICU admission } \\
\hline Nasal and mask oxygen therapy & $149(20.3)(17.4-23.2)$ & $81(23.9)(19.3-28.5)$ & $68(17.3)(13.5-21)$ & 0.026 \\
\hline HFNO & $320(43.7)(40.1-47.3)$ & $176(51.9)(46.6-57.3)$ & $144(36.5)(31.8-41.3)$ & $<0.001$ \\
\hline Non-invasive ventilation & $164(22.3)(19.3-25.4)$ & $57(16.8)(12.8-20.8)$ & $107(27.2)(22.7-31.2)$ & 0.001 \\
\hline Invasive machinal ventilation & $100(13.6)(11.2-16.1)$ & $25(7.4)(4.6-10.2)$ & 75 (19) $(15.1-22.9)$ & $<0.001$ \\
\hline \multicolumn{5}{|l|}{ Life sustaining treatment during ICU stay } \\
\hline Invasive mechanical ventilation, $n(\%)(95 \% \mathrm{Cl})$ & $307(41.9)(38.3-45.5)$ & $59(17.4)(13.5-21.9)$ & $248(62.9)(58-67.7)$ & $<0.001$ \\
\hline Duration of IMV, day, median (IQR) & $7(3-12)$ & $9(5-15)$ & $6(3-11)$ & $<0.001$ \\
\hline PEEP, $\mathrm{cmH}_{2} \mathrm{O}$, median (IQR) & $10(9-12)$ & $10(8-12)$ & $10(9-12)$ & 0.355 \\
\hline $\mathrm{FiO}_{2}, \%$, median (IQR) & $90(70-100)$ & $80(70-100)$ & $100(75-100)$ & $<0.001$ \\
\hline Tidal volume, ml, median (IQR) & $400(370-450)$ & $420(400-450)$ & $400(360-450)$ & 0.497 \\
\hline Vasopressor, $n(\%)(95 \% \mathrm{Cl})$ & 297 (40.4) (36.8-44) & $41(12.1)(8.8-16)$ & $255(64.7)(59.8-69.4)$ & $<0.001$ \\
\hline CRRT, $n$ (\%) (95\%Cl) & 95 (13) (10.6-15.6) & $18(5.3)(3.2-8.3)$ & $77(19.5)(15.7-23.8)$ & $<0.001$ \\
\hline $\mathrm{ECMO}, n(\%)(95 \% \mathrm{Cl})$ & $35(4.8)(3.3-6.6)$ & $13(3.8)(2.1-6.5)$ & $22(5.6)(3.5-8.3)$ & 0.268 \\
\hline Viral negative conversion rate, $n / N(\%)$ & $226 / 341(66.3)$ & 193/215 (89.8) & $33 / 126(26.2)$ & $<0.001$ \\
\hline Duration of HFNO and NIV before IMV, days, median (IQR) & $4(1-7)$ & $2(0-8)$ & $4(1-7)$ & 0.039 \\
\hline ICU length of stay, days, median (IQR) & $12(6-25)$ & $27(13-28)$ & $7(4-12)$ & $<0.001$ \\
\hline
\end{tabular}

IQR interquartile range, $\mathrm{Cl}$ confidence interval, $C R R T$ continuous renal replacement therapy, $E C M O$ extracorporeal membrane oxygenation, FiO ${ }_{2}$ fraction of inspired oxygen, HFNO high flow nasal oxygen, ICU, intensive care unit, IMV invasive mechanical ventilation, $P E E P$ positive end expiratory pressure

D-dimer and hsc-TnI levels were relatively stable, but significantly higher in non-survivors than survivors. In the joint longitudinal model, there was significant difference between survivors and nonsurvivors with regards to dynamic changes of $\mathrm{PaO}_{2} / \mathrm{FiO}_{2}$ ratio, hs-CRP, $\mathrm{LDH}$, D-dimer and hsc-TnI levels, but not lymphocyte count, over time during ICU stay (Fig. 2). Proportion of survivors and non-survivors receiving life-sustaining treatment are shown in Figure S3.

\section{Discussion}

In this large sample of 733 critically ill patients with COVID-19, we reported a high 28-day mortality of $53.8 \%$, which might be explained by the high prevalence of organ dysfunction such as respiratory failure, shock and acute renal failure. In addition, independent risk factors of mortality were also identified.

The variation of mortality in critically ill patients with viral pneumonia might be explained, at least in part, by different etiologies. Current data suggested that pneumonia caused coronavirus was associated with a higher mortality than influenza virus. Yang et al. observed a 28-day mortality of $61.5 \%$ among 52 critically ill patients with COVID-19 [4], while two case series from the United States reported mortality of $50 \%$ and $67 \%$, respectively $[3,5]$. Likewise, pneumonia caused by the other two coronaviruses, i.e. SARS-CoV and MERS-CoV, was also associated with high mortality [">11-15]. In comparison, a much lower mortality (i.e. 17-40\%) was reported in critically ill patients with influenza A (H1N1) pneumonia [16-18].

Acute respiratory failure represented the most common organ failure in patients with COVID-19. Therefore, mechanical ventilation was the mainstay in the treatment of severe hypoxemia. However, timing of IMV still remained controversial. Among 307 patients (41.9\%) who received IMV during ICU stay in our study, duration of HFNO and NIV before IMV was 2 days longer in nonsurvivors, suggesting that delayed intubation might be associated with poor clinical outcome in patients with COVID-19. This was consistent with the interim guidance of WHO and China $[7,19]$, which strongly recommended that patients treated with HFNO or NIV should be closely monitored for clinical deterioration due to the high risk of treatment failure, and endotracheal intubation should be considered if the patient acutely deteriorated or did not improve after a short trial.

Apart from acute respiratory failure, critically ill patients also developed other organ dysfunction and/ or failure, such as cardiac injury/shock, and acute renal failure. Almost $60 \%$ of patients in our study had evidence of cardiac injury (i.e. elevated hsc-TnI level), a common 

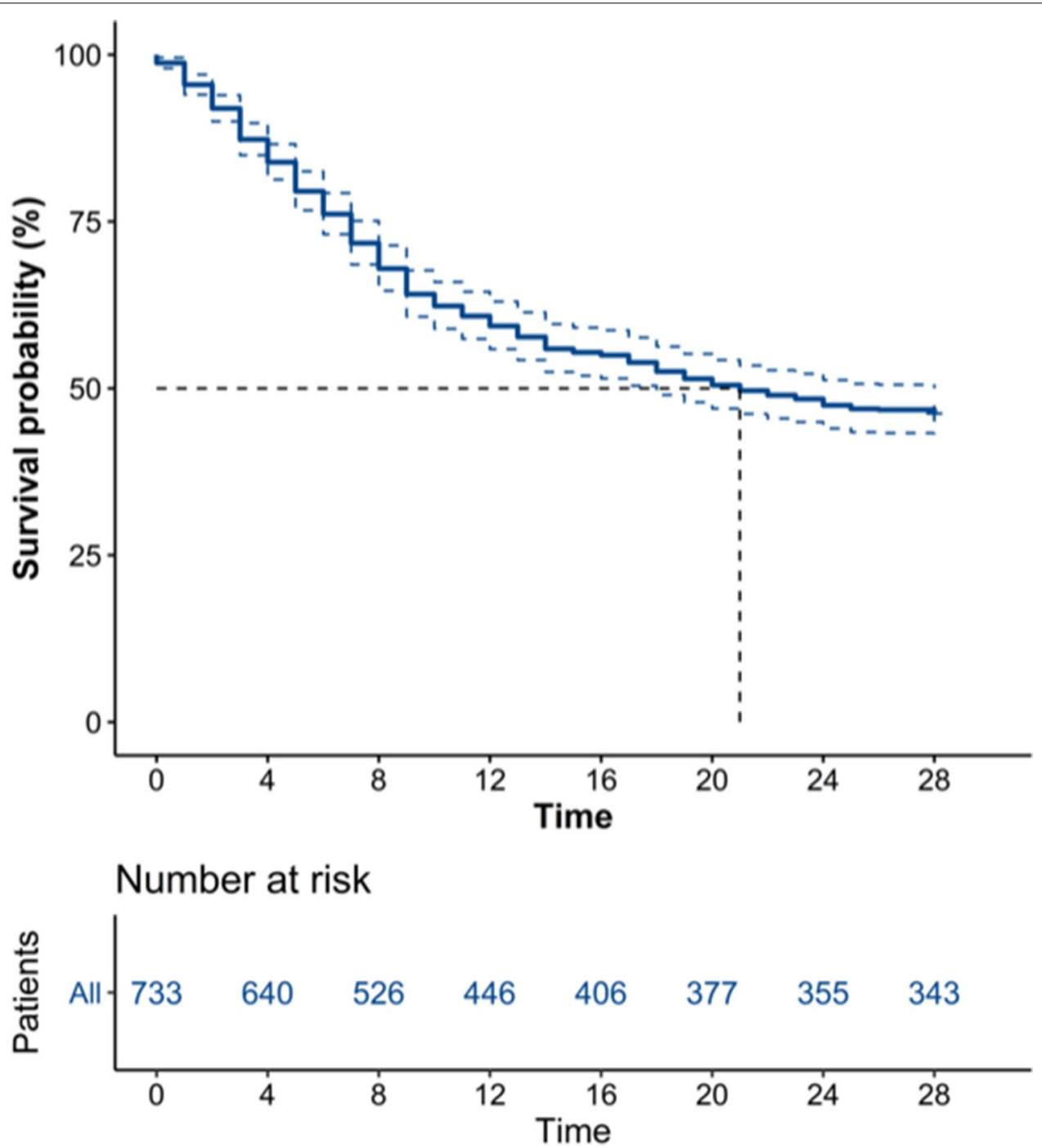

Fig. 1 Survival of critically ill patients with COVID-19 admitted to ICU. Dashed lines represent 95\% CI

finding in previous studies of critically ill patients with COVID-19 [20-22]. Potential mechanisms of cardiac injury in patients with COVID-19 remained to be elucidated, but might be related to fulminant myocarditis due to direct viral infection, as well as type 2 myocardial infarction due to imbalance between myocardial oxygen supply and demand [23]. In addition, prevalence of cardiac injury was $63 \%$ in patients infected with influenza A (H7N9) virus, which was associated with lower probability of virus clearance and higher mortality [24]. In contrast, cardiac injury had not been reported in patients with SARS or MERS. Although it was possible that SARS-CoV-2 might cause injury to target organs different from that of SARS-CoV and MERS-CoV, a more plausible explanation would be the limited, if any, use of biomarkers of cardiac injury (e.g. hsc-TnI) in previous studies.
We compared changes of laboratory tests, organ dysfunction, and life-sustaining treatment over time in survivors and non-survivors. The changes of lymphocyte count and D-dimer level were similar to that in previous studies [25-27]. Our results further suggested persistent lymphocytopenia, hypoxemia, inflammation and cell injury might help discriminate those patients with poor treatment response and grave outcome. In addition, the pattern of organ dysfunction/failure as well as life-sustaining treatment over time improved our understanding of the demand of critical care resource among critically ill patients with COVID-19. We believed that these data might help those experiencing a surge of critically ill cases with COVID-19 to make a better preparation with regards to medical devices, medications, and human power. 
Table 3 Univariate and multivariate Cox regression proportional-hazards model of risk factors associated with 28-day mortality in COVID-19 patients

\begin{tabular}{|c|c|c|c|c|c|c|c|c|}
\hline \multirow[t]{2}{*}{ Variables } & \multicolumn{4}{|c|}{ Univariate } & \multicolumn{4}{|c|}{ Multivariate } \\
\hline & HR & $95 \% \mathrm{C}$ & & $P$ value & HR & $95 \% \mathrm{Cl}$ & & $P$ value \\
\hline Age & 1.038 & 1.029 & 1.047 & $<0.001$ & 1.024 & 1.015 & 1.034 & $<0.001$ \\
\hline Male & 1.278 & 1.030 & 1.586 & 0.026 & & & & \\
\hline Hypertension & 1.375 & 1.126 & 1.679 & 0.002 & & & & \\
\hline Malignancies & 1.909 & 1.174 & 3.106 & 0.009 & 1.950 & 1.186 & 3.204 & 0.008 \\
\hline Smoking & 1.553 & 1.081 & 2.230 & 0.017 & & & & \\
\hline SOFA & 1.218 & 1.184 & 1.252 & $<0.001$ & & & & \\
\hline APACHE II & 1.104 & 1.090 & 1.119 & $<0.001$ & 1.037 & 1.011 & 1.063 & 0.005 \\
\hline $\mathrm{PaO}_{2} / \mathrm{FiO}_{2}$ ratio & 0.993 & 0.992 & 0.995 & $<0.001$ & 0.996 & 0.995 & 0.998 & $<0.001$ \\
\hline Lymphocyte & 0.874 & 0.722 & 1.057 & 0.164 & & & & \\
\hline $\mathrm{LDH}$ & 1.000 & 1.000 & 1.000 & $<0.001$ & & & & \\
\hline Albumin & 0.8958 & 0.879 & 0.913 & $<0.001$ & 0.938 & 0.918 & 0.959 & $<0.001$ \\
\hline CRP & 1.005 & 1.004 & 1.007 & $<0.001$ & & & & \\
\hline \multicolumn{9}{|l|}{ INR $<0.97$, s, reference } \\
\hline $0.97-1.09, \mathrm{~s}$ & 1.522 & 1.085 & 2.137 & 0.015 & & & & \\
\hline $1.10-1.22, s$ & 1.941 & 1.391 & 2.707 & $<0.001$ & & & & \\
\hline$>1.22, \mathrm{~s}$ & 3.931 & 2.872 & 5.380 & $<0.001$ & & & & \\
\hline D-dimer & 1.021 & 1.016 & 1.025 & $<0.001$ & 1.006 & 1.000 & 1.011 & 0.035 \\
\hline \multicolumn{9}{|c|}{ Creatinine $<56.9$, umol/L, reference } \\
\hline 56.9-70.6, umol/L & 1.038 & 0.761 & 1.416 & 0.815 & & & & \\
\hline 70.7-93, umol/L & 1.453 & 1.084 & 1.948 & 0.012 & 1.411 & 1.014 & 1.962 & 0.041 \\
\hline$>93, \mathrm{umol} / \mathrm{L}$ & 2.207 & 1.659 & 2.936 & $<0.001$ & 1.636 & 1.167 & 2.293 & 0.004 \\
\hline \multicolumn{9}{|l|}{ hscTnl $<10.2$ reference } \\
\hline $10.2-27.7$ & 1.170 & 0.848 & 1.613 & 0.339 & & & & \\
\hline $27.8-103.5$ & 1.628 & 1.202 & 2.204 & 0.002 & & & & \\
\hline$>103.5$ & 3.182 & 2.388 & 4.240 & $<0.001$ & 1.453 & 1.048 & 2.014 & 0.025 \\
\hline NIV at ICU admission & 1.403 & 1.121 & 1.756 & 0.003 & & & & \\
\hline HFNO at ICU admission & 1.102 & 0.901 & 1.347 & 0.345 & & & & \\
\hline
\end{tabular}

APACHE acute physiological and chronic health evaluation, AST aspartate aminotransferase, CRP C-reactive protein, $F \mathrm{IO}_{2}$ fraction inspired oxygen concentration, INR international normalized ratio, $\mathrm{LDH}$ lactate dehydrogenase, $\mathrm{PaO}_{2}$ pulse oxygen saturation, $\mathrm{SOFA}$ sequential organ failure assessment

Previous studies showed that the relationship between sex and mortality remained controversial in patients with infection/sepsis. A retrospective study reported that male sepsis had a higher 90-day mortality rate than female. However, a study of 563,155 sepsis patients also reported that female was independently associated with increased mortality [28]. In line with patients with SARS, MERS or influenza A (H1N1) pneumonia [11, 17, 18], we found that male was not associated with increased mortality in critically ill patients with COVID-19. As in other studies [26], D-dimer were independent risk factors of mortality in patients with COVID-19.

Our study was subject to limitations. First, this was a retrospective study during a pandemic with $10-20 \%$ rate of missing data, which might introduce bias in study results. Second, we only enrolled patients who were admitted into ICU in January and February 2020, when medical resources were overwhelmed by the surge of COVID-19 cases. Critically ill patients with COVID-19 who were treated in the ICU in March and April might have a different disease pattern and, possibly, clinical outcome. Third, we did not collect data with regards to complications such as secondary infection, bleeding, and thromboembolism. As a matter of fact, coagulopathy and thromboembolism had been reported with prevalence up to $30 \%$ in ICU patients with COVID-19 [29, 30]. Forth, we did not report cause of death in critically ill patients with COVID-19. However, severe hypoxemia was the leading cause of death among critically ill patients with COVID-19 in our previous study, followed by circulatory shock [31]. Fifth, $13.6 \%$ of our patients still remained in the hospital at the end of follow-up, i.e. 28 days after ICU admission. Long-term clinical outcome might be only available with longer follow-up. 
a

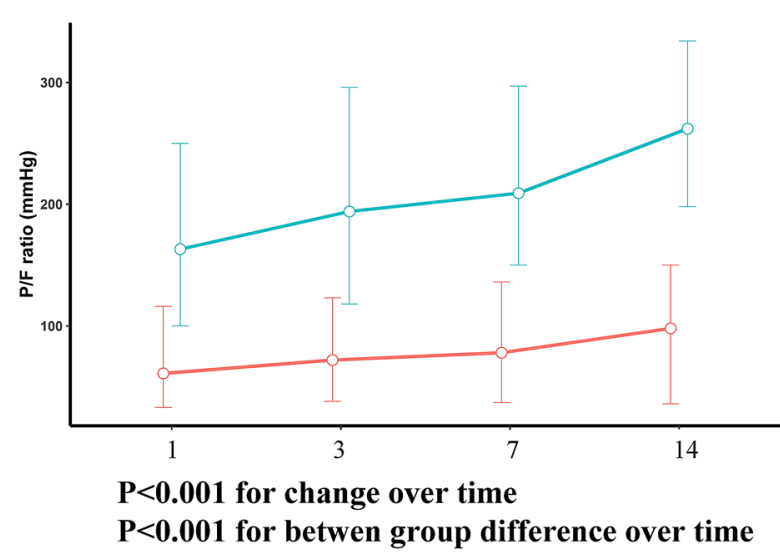

c

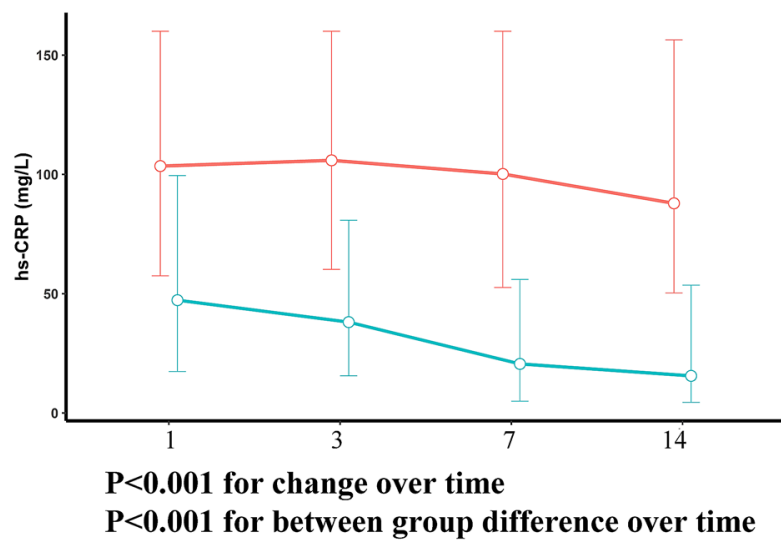

e

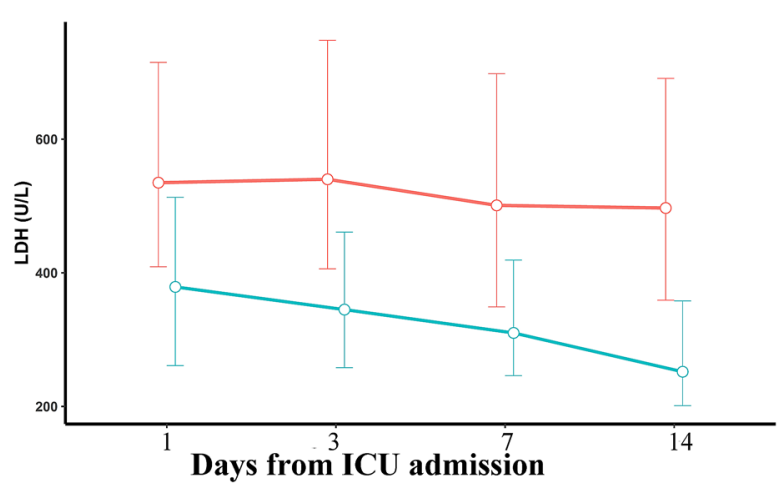

$P<0.001$ for change over time

$\mathbf{P}<\mathbf{0 . 0 0 1}$ for between group difference over time b

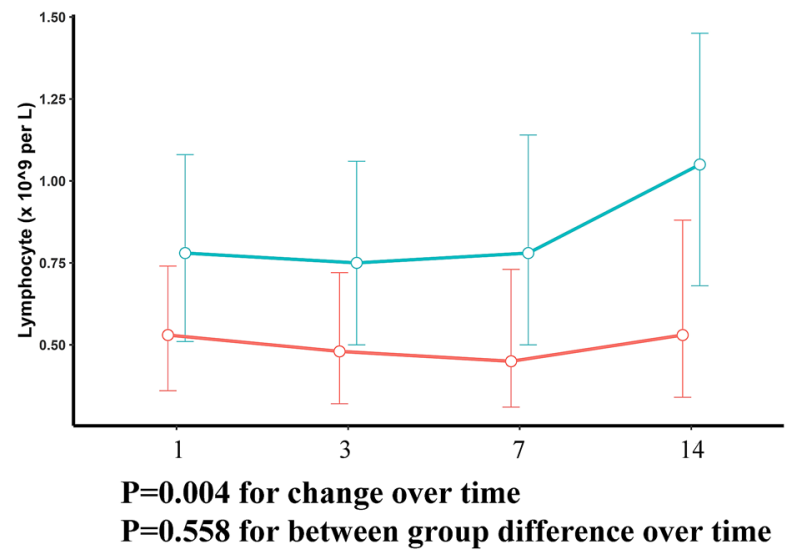

d

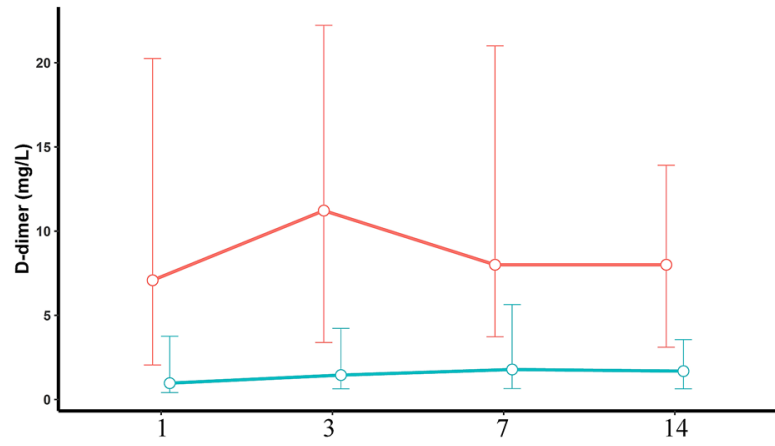

$\mathbf{P}<0.001$ for change over time

$\mathbf{P}<0.001$ for between group difference over time

f

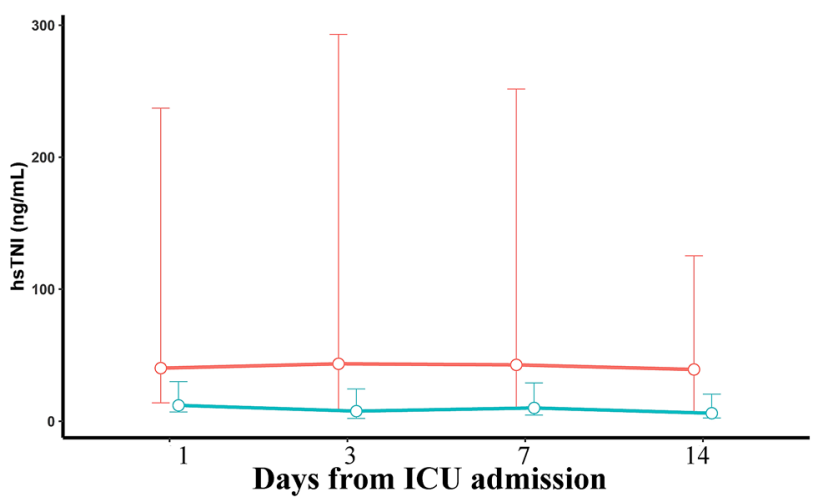

$P<0.001$ for change over time $\mathbf{P}<\mathbf{0 . 0 0 1}$ for between group difference over time

Fig. 2 Temporal changes in laboratory markers from ICU admission in critically ill patients with COVID-19. Figure shows temporal changes in P/F ratio (a), lymphocytes (b), hs-CRP (c), D-dimer (d), LDH (e), and hsc-Tnl (f). Differences between survivors and non-survivors were significant for all time points shown. $h s$-CRP high-sensitive C-reactive protein, LDH lactate dehydrogenase, $h s c-T n /$ high-sensitivity cardiac troponin I 
In conclusion, in this case series of critically ill patients with COVID-19 who were admitted into the ICU, more than half patients died at day 28 . The higher percentage of organ failure in these patients indicated a significant demand for critical care resources.

\section{Electronic supplementary material}

The online version of this article (https://doi.org/10.1007/s00134-020-06211-2) contains supplementary material, which is available to authorized users.

\begin{abstract}
Author details
1 Jiangsu Provincial Key Laboratory of Critical Care Medicine, Department of Critical Care Medicine, Zhongda Hospital, School of Medicine, Southeast University, Nanjing 210009, Jiangsu, China. ${ }^{2}$ Department of Critical Care Medicine, Wuhan Jin-Yintan Hospital, Wuhan 430071, China. ${ }^{3}$ Department of Critical Care Medicine, Tongji Hospital, Tongji Medical College Huazhong University of Science and Technology, Wuhan 430030, China. ${ }^{4}$ Department of Critical Care Medicine, Union Hospital, Tongji Medical College Huazhong University of Science and Technology, Wuhan 430022, China. ${ }^{5}$ Department of Infection Disease, Wuhan Pulmonary Hospital, Wuhan, China. ${ }^{6}$ Department of Critical Care Medicine, Shenzhen Third Hospital, Shenzhen, China. ${ }^{7}$ Department of Critical Care Medicine, Huangshi Hospital of Chinese Medicine, Huangshi 435000, China. ${ }^{8}$ Department of Critical Care Medicine, Huangshi Central Hospital, Huangshi 435000, China. ${ }^{9}$ Department of Respiratory and Critical Care Medicine, Beijing Institute of Respiratory Medicine, Beijing Chao-Yang Hospital, Capital Medical University, Beijing 100020, China ${ }^{10}$ Department of Critical Care Medicine, Xuanwu Hospital, Capital Medical University, Beijing 100053, China. ${ }^{11}$ Emergency Department, The 900th Hospital of Joint Service Corps of Chinese PLA, Fuzhou 350025, China. ${ }^{12}$ Department of Critical Care Medicine, Zhongshan Hospital, Fudan University, Shanghai 200032, China. ${ }^{13}$ Department of Critical Care Medicine, Guangzhou Institute of Respiratory Health, The First Affiliated Hospital of Guangzhou Medical University, Guangzhou 510120, China. ${ }^{14}$ Department of Critical Care Medicine, The First Affiliated Hospital, College of Medicine, Zhejiang University, Hangzhou 310003, China. ${ }^{15}$ Department of Critical Care Medicine, Northern Jiangsu People's Hospital, Clinical Medical School, Yangzhou University, Yangzhou 225001, China. ${ }^{16}$ Medical ICU, Peking Union Medical College Hospital, Peking Union Medical College and, Chinese Academy of Medical Sciences, Beijing 100730, China.
\end{abstract}

\section{Acknowledgements}

We shall thank all the doctors, nurses and clinical scientists who worked in the hospital during the period of patient recruitment as well as the patients who were involved in this study.

\section{Author contributions}

JX, WW, SL, YH, MH, JL, ZT, HQ and BD had the idea for and designed the study ZT, BD and HQ supervised the study; JX, YW and HK did the statistical analysis. All authors contributed to acquisition, analysis, or interpretation of data. JX and BD wrote the manuscript. All authors revised the report and approved the final version before submission.

\section{Funding}

This work was supported by Key Research and Development Plan of Jiangsu Province (BE2018743 and BE2019749) and Chinese Academy of Medical Sciences (CAMS) Innovation Fund for Medical Sciences (CIFMS) from China Academy of Medical Sciences and Peking Union Medical College (CN) (2020I2M-2-005 and 2019-12M-1-001).

\section{Compliance with ethical standards}

\section{Conflicts of interest}

We declare no competing interests.

\section{Ethical statement}

Approval of the ethics committee of Jin Yin-tan Hospital (KY-2020-10.02) Wuhan, China.

\section{Publisher's Note}

Springer Nature remains neutral with regard to jurisdictional claims in published maps and institutional affiliations.

Received: 28 April 2020 Accepted: 4 August 2020

Published online: 20 August 2020

\section{References}

1. Huang C, Wang Y, Li X, Ren L, Zhao J, Hu Y, Zhang L, Fan G, Xu J, Gu X, Cheng Z, Yu T, Xia J, Wei Y, Wu W, Xie X, Yin W, Li H, Liu M, Xiao Y, Gao H, Guo L, Xie J, Wang G, Jiang R, Gao Z, Jin Q, Wang J, Cao B (2020) Clinical features of patients infected with 2019 novel coronavirus in Wuhan, China. Lancet 395:497-506

2. WHO. WHO Coronavirus Disease (COVID-19) Dashboard. Available at https://covid19.who.int. Accessed 19 July 2020

3. Arentz M, Yim E, Klaff L, Lokhandwala S, Riedo FX (2020) Characteristics and outcomes of 21 critically ill patients with COVID-19 in Washington State. JAMA 323:1612-1614

4. Yang $X, Y u Y$, Xu J, Shu H, Xia J, Liu H, Wu Y, Zhang L, Yu Z, Fang M, Yu T, Wang Y, Pan S, Zou X, Yuan S, Shang Y (2020) Clinical course and outcomes of critically ill patients with SARS-CoV-2 pneumonia in Wuhan, China: a single-centered, retrospective, observational study. Lancet Respir Med 8:475-481

5. Bhatraju PK, Ghassemieh BJ, Nichols M, Kim R, Jerome KR, Nalla AK, Greninger AL, Pipavath S, Wurfel MM, Evans L, Kritek PA, West TE, Luks A, Gerbino A, Dale CR, Goldman JD, O'Mahony S, Mikacenic C (2020) Covid19 in critically ill patients in the Seattle region-case series. N Engl J Med 382:2012-2022

6. Grasselli G, Zangrillo A, Zanella A, Antonelli M, Cabrini L, Castelli A, Cereda D, Coluccello A, Foti G, Fumagalli R, lotti G, Latronico N, Lorini L, Merler S, Natalini G, Piatti A, Ranieri MV, Scandroglio AM, Storti E, Cecconi M, Pesenti A, Network C-LI (2020) Baseline characteristics and outcomes of 1591 patients infected with SARS-CoV-2 admitted to ICUs of the Lombardy region, Italy. JAMA 323:1574-1581

7. Diagnosis and management protocol of COVID-19 in China. https://www nhc.gov.cn/yzygj/s7653p/202003/46c9294a7dfe4cef80dc7f5912eb19 89.shtml

8. Rice TW, Wheeler AP, Bernard GR, Hayden DL, Schoenfeld DA, Ware LB, National Institutes of Health NHL, Blood Institute AN (2007) Comparison of the $\mathrm{SpO}_{2} / \mathrm{FiO}_{2}$ ratio and the $\mathrm{PaO}_{2} / \mathrm{FiO}_{2}$ ratio in patients with acute lung injury or ARDS. Chest 132:410-417

9. Moreno R, Vincent JL, Matos R, Mendonca A,Cantraine F, Thijs L, Sprung C,Antonelli M, Bruining and medicine $H$, Willatts S (1999) The use of maximum SOFA score to quantify organ dysfunction/failure in intensive care. Results of a prospective, multicentre study. In': Working group on sepsis related problems of the ESICM25, pp 686-696

10. Al-Tawfiq JA, Hinedi K, Ghandour J, Khairalla H, Musleh S, Ujayli A, Memish ZA (2014) Middle East respiratory syndrome coronavirus: a case-control study of hospitalized patients. Clin Infect Dis 59:160-165

11. Zhang Z, Reinikainen J, Adeleke KA, Pieterse ME, Groothuis-Oudshoorn CGM (2018) TIme-varying covariates and coefficients in Cox regression models. Ann Transl Med 6:121

12. Assiri A, Al-Tawfiq JA, Al-Rabeeah AA, Al-Rabiah FA, Al-Hajjar S, Al-Barrak A, Flemban H, Al-Nassir WN, Balkhy HH, Al-Hakeem RF, Makhdoom HQ, Zumla Al, Memish ZA (2013) Epidemiological, demographic, and clinical characteristics of 47 cases of Middle East respiratory syndrome coronavirus disease from Saudi Arabia: a descriptive study. Lancet Infect Dis 13:752-761

13. Tsang OT, Chau TN, Choi KW, Tso EY, Lim W, Chiu MC, Tong WL, Lee PO, Lam BH, Ng TK, Lai JY, Yu WC, Lai ST (2003) Coronavirus-positive nasopharyngeal aspirate as predictor for severe acute respiratory syndrome mortality. Emerg Infect Dis 9:1381-1387

14. Al-Abdallat MM, Payne DC, Alqasrawi S, Rha B, Tohme RA, Abedi GR, Al Nsour M, Iblan I, Jarour N, Farag NH, Haddadin A, Al-Sanouri T, Tamin A, Harcourt JL, Kuhar DT, Swerdlow DL, Erdman DD, Pallansch MA, Haynes LM, Gerber SI, Jordan M-CIT (2014) Hospital-associated outbreak of Mid dle East respiratory syndrome coronavirus: a serologic, epidemiologic, and clinical description. Clin Infect Dis 59:1225-1233 
15. Manocha S, Walley KR, Russell JA (2003) Severe acute respiratory distress syndrome (SARS): a critical care perspective. Crit Care Med 31:2684-2692

16. Li SH, Hsieh MJ, Lin SW, Chuang LP, Lee CS, Chiu LC, Chang CH, Hu HC, Huang CC, Kao KC (2020) Outcomes of severe H1N1 pneumoniae: a retrospective study at intensive care units. J Formos Med Assoc 119:26-33

17. Kumar A, Zarychanski R, Pinto R, Cook DJ, Marshall J, Lacroix J, Stelfox T, Bagshaw S, Choong K, Lamontagne F, Turgeon AF, Lapinsky S, Ahern SP, Smith O, Siddiqui F, Jouvet P, Khwaja K, McIntyre L, Menon K, Hutchison J, Hornstein D, Joffe A, Lauzier F, Singh J, Karachi T, Wiebe K, Olafson K, Ramsey C, Sharma S, Dodek P, Meade M, Hall R, Fowler RA, Canadian Critical Care Trials Group HNC (2009) Critically ill patients with 2009 influenza A(H1N1) infection in Canada. JAMA 302:1872-1879

18. Dominguez-Cherit G, Lapinsky SE, Macias AE, Pinto R, Espinosa-Perez L, de la Torre A, Poblano-Morales M, Baltazar-Torres JA, Bautista E, Martinez A, Martinez MA, Rivero E, Valdez R, Ruiz-Palacios G, Hernandez M, Stewart TE, Fowler RA (2009) Critically ill patients with 2009 influenza A(H1N1) in Mexico. JAMA 302:1880-1887

19. WHO. Clinical management of COVID-19: interim quidance, 27 May 2020. Available at https://apps.who.int/iris/rest/bitstreams/1278777/retrieve. Accessed 22 June 2020

20. Shi S, Qin M, Shen B, Cai Y, Liu T, Yang F, Gong W, Liu X, Liang J, Zhao Q, Huang H, Yang B, Huang C (2020) Association of cardiac injury with mortality in hospitalized patients with COVID-19 in Wuhan. China. JAMA Cardiol 5(7):802-810

21. Ruan Q, Yang K, Wang W, Jiang L, Song J (2020) Clinical predictors of mortality due to COVID-19 based on an analysis of data of 150 patients from Wuhan, China. Intensive Care Med 46:846-848

22. Bonow RO, Fonarow GC, O'Gara PT, Yancy CW (2020) Association of coronavirus disease 2019 (COVID-19) with myocardial injury and mortality. JAMA Cardiol. https://doi.org/10.1001/jamacardio.2020.1105

23. Libby $P$ (2020) The Heart in COVID19: Primary target or secondary bystander? JACC Basic Transl Sci 5:537-542
24. Gao C, Wang Y, Gu X, Shen X, Zhou D, Zhou S, Huang JA, Cao B, Guo Q, Community-Acquired Pneumonia-China N (2020) Association between cardiac injury and mortality in hospitalized patients infected with avian influenza A (H7N9) Virus. Crit Care Med 48:451-458

25. Zhou F, Yu T, Du R, Fan G, Liu Y, Liu Z, Xiang J, Wang Y, Song B, Gu X, Guan L, Wei Y, Li H, Wu X, Xu J, Tu S, Zhang Y, Chen H, Cao B (2020) Clinical course and risk factors for mortality of adult inpatients with COVID-19 in Wuhan, China: a retrospective cohort study. Lancet 395:1054-1062

26. Wang D, Hu B, Hu C, Zhu F, Liu X, Zhang J, Wang B, Xiang H, Cheng Z, Xiong Y, Zhao Y, Li Y, Wang X, Peng Z (2020) Clinical characteristics of 138 hospitalized patients with 2019 novel coronavirus-infected pneumonia in Wuhan, China. JAMA 323:1061-1069

27. Wang K, Zhang ZG, Yu MQ, Tao Y, Xie M (2020) 15-day mortality and associated risk factors for hospitalized patients with COVD-19 in Wuhan, China: an ambispective observational cohort study. Intensive Care Med 46(7):1472-1474

28. Ford DW, Goodwin AJ, Simpson AN, Johnson E, Nadig N, Simpson KN (2016) A severe sepsis mortality prediction model and score for use with administrative data. Crit Care Med 44:319-327

29. Klok FA, Kruip MJHA, van der Meer NJM, Arbouts MS, Gommers DAMPJ, Kant KM, Kaptein FHJ (2020) Incidence of thrombotic complications in critically ill ICU patients with COVID-19. Thromb Res 191:145-147

30. Helms J, Tacquard C, Severac F, Leonard-Lorant I, Ohana M, Delabranche X, Merdji H, Clere-Jehl R, Schenck M, Fagot Gandet F, Fafi-Kremer S, Castelain V, Schneider F, Grunebaum L, Anglés-Cano E, Sattler L, Mertes PM, Meziani F, CRICS TRIGGERSEP Group (2020) High risk of thrombosis in patients in severe SARS-CoV-2 infection: a multicenter prospective cohort study. Intensive Care Med 46(6):1089-1098

31. Xie J, Tong Z, Guan X, Du B, Qiu H (2020) Clinical characteristics of patients who died of coronavirus disease 2019 in China. JAMA Netw Open 3(4):e205619 